\title{
Multi-function oxidases are responsible for the synergistic interactions occurring between repellents and insecticides in mosquitoes
}

\author{
Julien Bonnet*1, Cédric Pennetier ${ }^{1,4,5}$, Stéphane Duchon ${ }^{1}$, Bruno Lapied ${ }^{3}$ and \\ Vincent Corbel $* 2$
}

\begin{abstract}
Address: ${ }^{1}$ Laboratoire de Lutte contre les Insectes Nuisibles, Institut de Recherche pour le Développement, 911 Avenue Agropolis, BP 64501 , 34394 Montpellier, France, ${ }^{2}$ Centre de Recherches Entomologiques de Cotonou (CREC), Institut de Recherche pour le Développement (IRD), 01 BP 4414 RP, Cotonou, Benin, ${ }^{3}$ Laboratoire RCIM UPRES EA 2647/USC INRA 2023, IFR 149 QUASAV, 49045 Angers, cedex, France, ${ }^{4}$ University of Greenwich at Medway, Central Avenue, Chatham, Kent ME4 4TB, England, UK and ${ }^{5}$ School of Life Science, University of Sussex, Brighton, BN1 9QG, England, UK
\end{abstract}

Email: Julien Bonnet* - jjulienbonnet@yahoo.fr; Cédric Pennetier - C.Pennetier@sussex.ac.uk; Stéphane Duchon - duchon@ird.fr; Bruno Lapied - bruno.lapied@univ-angers.fr; Vincent Corbel* - corbel@ird.fr

* Corresponding authors

Published: 16 April 2009

Parasites \& Vectors 2009, 2:17 doi:10.1186/1756-3305-2-17
Received: 19 February 2009

Accepted: 16 April 2009

This article is available from: http://www.parasitesandvectors.com/content/2/1/17

(C) 2009 Bonnet et al; licensee BioMed Central Ltd.

This is an Open Access article distributed under the terms of the Creative Commons Attribution License (http://creativecommons.org/licenses/by/2.0), which permits unrestricted use, distribution, and reproduction in any medium, provided the original work is properly cited.

\begin{abstract}
Background: With the spread of pyrethroid resistance in mosquitoes, the combination of an insecticide (carbamate or organophosphate) with a repellent (DEET) is considered as a promising alternative strategy for the treatment of mosquito nets and other relevant materials. The efficacy of these mixtures comes from the fact that they reproduce pyrethroid features and that positive interactions occur between insecticides and repellent. To better understand the mechanisms involved and assess the impact of detoxifying enzymes (oxidases and esterases) in these interactions, bioassays were carried out in the laboratory against the main dengue vector Aedes aegypti.
\end{abstract}

Methods: Topical applications of DEET and propoxur (carbamate), used alone or as a mixture, were carried out on female mosquitoes, using inhibitors of the two main detoxification pathways in the insect. PBO, an inhibitor of multi-function oxidases, and DEF, an inhibitor of esterases, were applied one hour prior to the main treatment.

Results: Results showed that synergism between DEET and propoxur disappeared in the presence of PBO but not with DEF. This suggests that oxidases, contrary to esterases, play a key role in the interactions occurring between DEET and cholinesterase inhibitors in mosquitoes.

Conclusion: These findings are of great interest for the implementation of "combination nets" in the field. They support the need to combine insecticide with repellent to overcome insecticide resistance in mosquitoes of public health importance. 


\section{Background}

Pyrethroids are currently the only insecticides recommended by the World Health Organization for the treatment of insecticidal materials against mosquitoes of public health importance [1]. The great success of pyrethroids is related to their strong efficacy at low dose, fast killing effect and relative low cost of production. Their low toxicity to humans and stability over time ensure a safe and effective personal protection against a wide range of pests and vectors [2]. Since the 1980s, they have been widely used for house spraying and impregnation of mosquito nets for malaria control [3].

Unfortunately, pyrethroid resistance is now widespread in mosquitoes. Mechanisms of resistance involve target site modification due to mutation within structural receptor genes and metabolic resistance via increased detoxification of insecticides [4]. Resistance represents a serious obstacle for vector control as demonstrated recently with insecticide-treated mosquito nets and indoor residual sprayings in Benin [5], as well as control of Aedes aegypti during space spraying in the Caribbean [6].

In this context, new molecules and strategies are urgently needed to preserve the efficacy of insecticide-treated materials used in public health [7]. Among the different strategies proposed, the combination of a repellent with a carbamate or an organophosphate (OP) on treated materials showed promising results for malaria vector control under simulated field conditions $[8,9]$. The strong killing effect of cholinesterase inhibitors added to the high personal protection of repellents reproduced pyrethroid features against several mosquito vectors. For example, a mixture of DEET (the gold standard for synthetic repellent) and propoxur (carbamate) showed equivalent toxicity to deltamethrin at the dose that killed $100 \%\left(\mathrm{LD}_{100}\right)$ of susceptible Ae. Aegypti. Moreover, on the kdr homozygous strain of the same species, the mixture performed significantly better than deltamethrin [10]. This strong efficacy was attributed to the synergistic interactions occurring between propoxur and DEET. These interactions were also observed between an organophosphate, pyrimiphosmethyl and the two repellents DEET and picaridin ${ }^{\circledR}$ on bed nets against Anopheles gambiae in both laboratory and field experiments, confirming that this strategy may be promising for the control of pyrethroid resistant mosquitoes $[8,9]$.

However, the physiological mechanisms involved in these interactions remain unclear. While carbamates and OPs inhibit acetylcholinesterase in insects [11], controversies remain over DEET mode of action $[12,13]$ and toxicity in insects [14-16]. Recent studies showed that DEET toxicity may occur through a general perturbation of insect neuronal transmission $[17,18]$.
As previously described by Corbel et al. [19] with pyrethroid-carbamate combinations, synergistic interactions between molecules having different modes of action may result from a general physiological disruption, involving different target sites in the central nervous system. Another hypothesis is the involvement of detoxification enzymes. Indeed, one component of the mixture may interfere with the detoxification of the other, thereby increasing the toxicity of both $[20,21]$. Such involvement of esterases [22] or oxidases [23] has already been shown in synergism between pyrethroids and OPs. The OP prevents the degradation of the pyrethroid insecticide by competing as enzyme substrates.

In the present study, we investigated through toxicological bioassays (topical applications) the mechanisms involved in DEET and propoxur interactions by using two enzyme inhibitors (PBO and DEF) against the dengue and yellow fever vector, Aedes aegypti.

\section{Methods \\ Mosquitoes}

The susceptible strain, Bora, of Ae. aegypti, originating from French Polynesia, was used for this study. This strain has been colonized in the laboratory for many years and is free of any detectable resistance mechanisms.

\section{Insecticide, repellent and enzyme inhibitors}

Bioassays were carried out with technical grades of active ingredients diluted in acetone. Propoxur (2-isopropoxyphenylmethylcarbamate) $99.6 \%$ was provided by Bayer CropScience (Monheim, Germany). DEET (N,N-diethylm-toluamide) 97\% was provided by Sigma-Aldrich (Saint Quentin Fallavier, France). Enzyme inhibitors, piperonyl butoxide (5-((2-(2-butoxyethoxy)ethoxy)methyl)-6-propyl-1,3-benzodioxole) $90 \%$ and S,S,S-tributyl phosphorotrithioate 98.1\% were purchased from Fluka (Buchs, Switzerland) and Chem Service (West Chester, PA, USA). Piperonyl butoxide (PBO) is a well known inhibitor of cytochrome-P450 monooxygenases (multi-function oxidases), widely used as a synergist for insecticide treatments [24]. S,S,S-tributyl phosphorotrithioate (DEF) is a specific inhibitor of esterases.

\section{Topical applications}

Topical applications were used to measure the interactions occurring between technical insecticide and repellent on Ae. aegypti. This method allows estimating the intrinsic toxicity of a product excluding all other effects linked to mosquito's behaviour, especially when exposed to an irritating or repellent compound. For each product alone or in a mixture, five to eight doses were tested to provide a range of mortality from nil to $100 \%$. Nonblood-fed females of Ae. aegypti, aged 2-5 days, were first anaesthetised by extended contact with carbon dioxide 
and deposited on a chilled plate $\left(4^{\circ} \mathrm{C}\right)$ maintaining anaesthesia during manipulation. Fifty females were used for each dose tested. A volume of $0.1 \mu \mathrm{l}$ of acetone solution (containing the product(s) at the required concentration(s)) was applied on the upper part of female's pronotum using a micro-capillary tube. Fifty females that received $0.1 \mu \mathrm{l}$ of pure acetone served as control. Enzyme inhibitors were applied at the maximal sub-lethal dose (1000 ng/female for PBO and $500 \mathrm{ng} /$ female for DEF) 1 hour before the main treatment using the same protocol. Females were preserved at $4{ }^{\circ} \mathrm{C}$ on the chilled plate during this interval of time, to ensure the diffusion of enzyme inhibitor through mosquito body prior to insecticide treatment. After manipulation, females were transferred into plastic cups, provided with sugar solution and held for 24 hours at $27^{\circ} \mathrm{C}$ and $80 \% \mathrm{RH}$. Mortality rates were recorded 24 hours after testing and corrected according to the formula of Abbott [25] in the case of a control mortality $>5 \%$. Data were expressed in nanograms of active ingredient per milligram of mosquito body weight. Three replicates were done for each test using different batches and generations of mosquitoes.

\section{Analysis of interactions}

Dose-effect regression lines of each product (insecticide and repellent) and their mixture were drawn using Probit software [26]. Data were analyzed according to the median-effect method of Chou and Talalay [27] using CalcuSyn software [28]. This software provides an estimation of the median-effect doses (Dm analogous to $\mathrm{LD}_{50}$ ) with their 95\% confidence intervals for each product and mixture. The median-effect equation states that:

$$
\log (F a / F u)=m \times \log (D x / D m)
$$

where $F a$ and $F u$ are the fractions of mosquitoes affected and unaffected respectively by the dose $D x$ of insecticide(s). $m$ represents the slope of the regression line and $D m$ the dose required to produce the median effect.

Insecticide, repellent and their mixture were evaluated in three conditions, i.e. first in absence of enzyme inhibitors, then following a pre-treatment of PBO or DEF. Three different binary mixtures of propoxur and DEET were prepared for each experimental situation (without synergist/ with $\mathrm{PBO} /$ with $\mathrm{DEF}$ ). The ratio of the mixture was determined by the ratio of the median effect doses of propoxur and DEET obtained in the situation considered. At the ratio chosen, both compounds are expected to make an equal contribution in killing mosquitoes.

The isobologram method of Chou and Talalay [27] was used to assess whether the interactions occurring between DEET and propoxur were synergistic, antagonistic or simply additive in the presence or absence of synergists (PBO and DEF). In this study, the use of isobologram was done as follows: diagonal lines connect doses of propoxur on the $\mathrm{x}$-axis to doses of DEET on the y-axis where each product is in theory equally efficient at killing mosquitoes when applied alone (e.g. isoboles $\mathrm{ED}_{50}, \mathrm{ED}_{75}$ and $\mathrm{ED}_{90}$ correspond to a dosage causing $50 \%, 75 \%$ and $90 \%$ mortality, respectively). The points relative to each line indicate how much of each product is required to achieve the same effect when applied in a mixture at the ratio chosen. Points below relative line indicate synergism, points close to relative line indicate additive effect, and points above relative line indicate antagonism between the compounds.

\section{Results}

The dose-effect regression lines for DEET, propoxur and their mixtures were fitted by straight lines (goodness of fit, $P>0.05)$. The highest mortality value in control batches was $13 \%$. The median-effect doses $(\mathrm{Dm})$ for these relationships are listed in Table 1.

The median-lethal doses on Ae. aegypti were 1.97 (1.782.19) ng a.i. per mg female for propoxur and 1189 (1088-1299) ng a.i. per mg female for DEET (Table 1). This result shows the toxicity at high dose of DEET against mosquitoes. According to these values, a binary mixture of propoxur and DEET was prepared at the ratio 1:600. The mixture was more potent at killing mosquitoes than one would expect in the case of a simple additive effect

Table I: Median-lethal doses of propoxur, DEET and their mixture on susceptible Ae. aegypti.

\begin{tabular}{cccc}
\hline Chemicals & Dm without synergists & Dm with PBO & Dm with DEF \\
propoxur & $1.97(1.78-2.19)$ & $0.27(0.17-0.42)$ & $1.01(0.83-1.24)$ \\
DEET & $1189(1088-1299)$ & $611(596-629)$ & $1078(1005-1155)$ \\
mixture & $319(296-343)$ & $406(385-428)$ & $128(119-136)$ \\
mixture ratio P:D & $1: 600$ & $1: 2000$ & $1: 1000$ \\
Slope of the regression lines $( \pm$ s.e. & $2.83(0.19)$ & $2.16(0.18)$ & $1.95(0.22)$ \\
propoxur & $4.16(0.42)$ & $3.98(0.12)$ & $3.18(0.20)$ \\
DEET & $3.32(0.18)$ & $3.76(0.20)$ & $2.96(0.14)$ \\
mixture & & &
\end{tabular}

Data are expressed in $\mathrm{ng}$ of active ingredient per $\mathrm{mg}$ of mosquito body weight ( $\pm 95 \%$ confidence intervals). 
(Figure 1A). This observation confirmed the occurrence of synergistic interactions between DEET and propoxur, regardless the dosage considered $\left(\mathrm{ED}_{50}, \mathrm{ED}_{75}\right.$ and $\left.\mathrm{ED}_{90}\right)$.

In the presence of PBO (1000 ng/female applied 1 hour before the treatment), the toxicity of propoxur and DEET significantly increased (Table 1). The median-lethal doses of propoxur [0.27 (0.17-0.42)] and DEET [611 (596629)] were about 7 and 2 times lower than that obtained without synergists. This indicates that cytochrome-P450 monooxygenases played a role in the detoxification of these two compounds. According to the values of medianlethal doses obtained with $\mathrm{PBO}$, a second mixture of propoxur and DEET was prepared (ratio 1:2000). In presence of $\mathrm{PBO}$, the mixture did not show any synergistic interactions in Ae. aegypti (Figure 1B). Conversely, slight antagonism was observed, the mixture being less efficacious at killing mosquitoes than expected in the case of a simple additive effect (Figure 1B).

Applying DEF at $500 \mathrm{ng} /$ female 1 hour prior to treatment with propoxur and DEET had little effect on toxicity of both compounds (Table 1). The median-lethal dose of propoxur [1.01 $(0.83-1.24)]$ was only 2 times lower than that observed without synergist whereas toxicity of DEET [1078 (1005-1155)] was unchanged. According to the values of median-lethal doses obtained with DEF, a third mixture of propoxur and DEET was prepared (ratio $1: 1000)$. In presence of DEF, the synergistic interactions between the compounds were maintained regardless of the dosage considered (Figure 1C).

\section{Discussion}

In the present study, topical applications of insecticide(s) were carried out on Ae. aegypti to better understand the physiological mechanisms involved in synergism between DEET and propoxur.

First, the Isobologram method of Chou and Talalay [27] confirmed the previous observations of Pennetier et al. [10] who demonstrated that the insecticidal activity of DEET and propoxur was enhanced when they are applied together. Our findings also showed that oxidases are able to metabolize the carbamate propoxur but also the repellent DEET, thus confirming previous works of Constantino et al. [29,30]. Conversely, esterases had little impact on toxicity of the two molecules. This can be explained by the absence of an ester bond in DEET which prevents any hydrolytic metabolism by esterases [30].

Most interestingly, pre-treatment with $\mathrm{PBO}$ suppressed the synergism previously observed between DEET and propoxur. According to these data, we suggest that cytochrome-P450 monooxygenases are responsible for the enhanced toxicity observed between the repellent and the carbamate. We assume that the competition between DEET and propoxur for the multi-function oxidases increased the toxicity of the mixture. Electrophysiological experiments are now in progress to identify the physiological events underlying DEET and carbamate toxicity in the insect central nervous system [31].

Cytochrome-P450 monooxygenases have been identified as being involved in strong pyrethroid resistance because they are over-expressed in wild resistant mosquitoes [3234]. Our results suggest that the activity of these enzymes is essential for the synergistic interactions between DEET and propoxur. Now, we can consider whether the overexpression of monooxygenases will enhance the toxicity of repellent and insecticide mixtures against mosquitoes. If yes, this suggests that these mixtures should be an effective tool to manage pyrethroid-resistance based on overexpression of multi-function oxidases. The next step should be to study the interactions between carbamates/OPs and repellents on mosquitoes in which oxidases are overexpressed.

\section{Conclusion}

As shown by Pennetier et al [10], the association of nonpyrethroid insecticide and repellent exhibited pyrethroid features, especially a fast killing effect and excito-repellency properties. The existence of positive interactions between the compounds is a major argument in favour of their possible use in public health. Reduced amounts of active ingredient would provide an effective protection for the treatment of mosquito nets and other relevant materials. The fact that multi-function oxidases are involved in these interactions (and not insecticide-target sites) is of great interest for the implementation of "combination nets" in the field and the management of insecticide resistance in mosquitoes.

In areas where resistance to pyrethroids can no longer be controlled, the use of carbamate (or organophosphate) combined to repellents appears as an effective alternative to pyrethroids, as they show efficacy equivalent to these insecticides in simulated field situations $[8,9]$. In other situations, such combinations might also be used as a supplement to pyrethroids to retard the spread of resistance. Further investigations in live situations are certainly necessary prior to the use of insecticide and repellent combinations for vector control. The efficacy of these mixtures against mosquitoes has to be assessed in the field on a significant period of time, as well as its cost and safety to human. However, we think that they offer significant advantages for public health intervention. First, as no pyrethroid insecticides are used, their efficacy would not be altered by $k d r$ mutation widespread in mosquito populations [35-37]. Using such combinations may also be of great interest in areas where mosquito populations show 

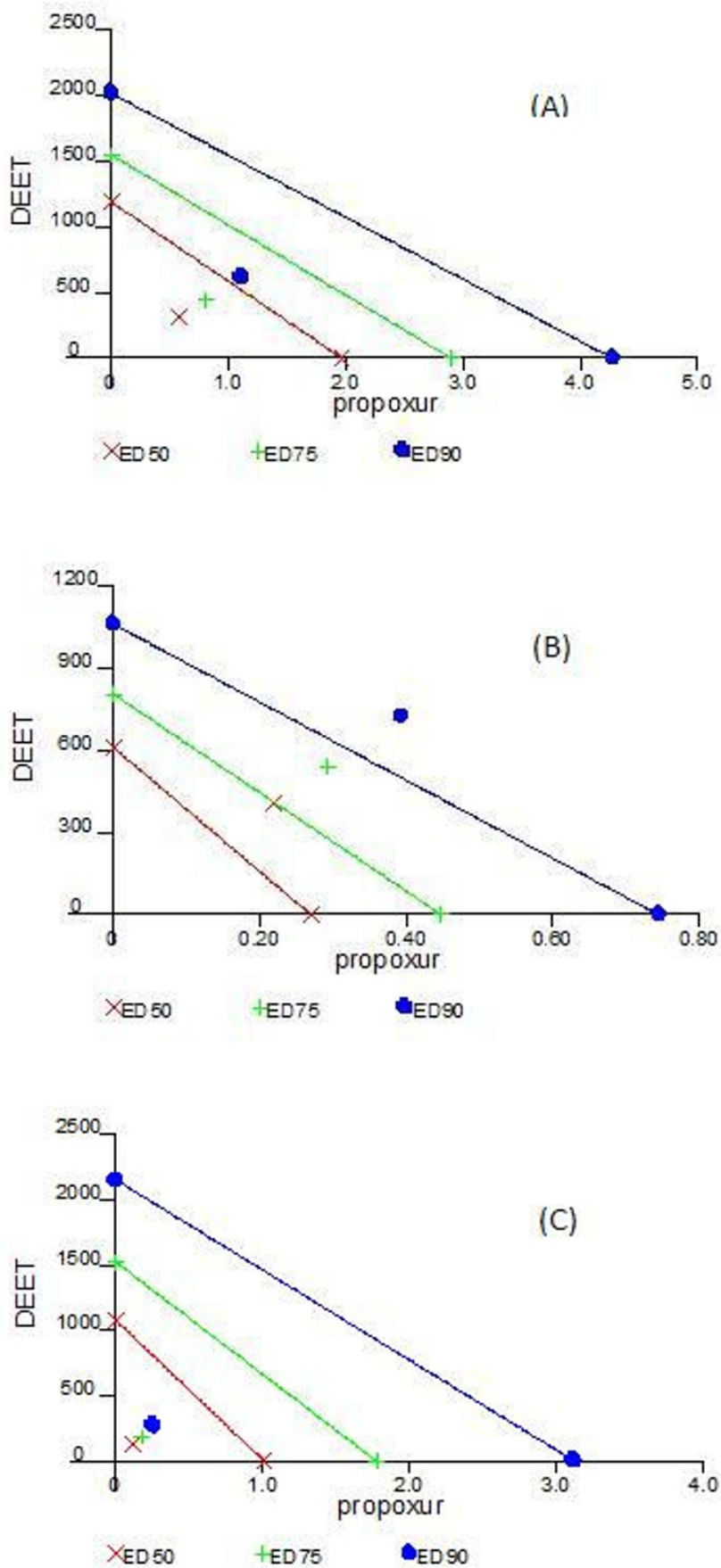

\section{Figure I}

Isobolograms of insecticidal activity for propoxur, DEET and their mixtures on Ae. aegypti. In absence of synergist (A), with PBO (B) and with DEF (C). Diagonal lines connect doses of equipotent activity for each product applied alone. Relative symbols indicate the amount of each product required to induce the same effect in a mixture (at the ratio based on median-effect doses of each product). Points below relative line indicate synergism, points close to relative line indicate additive effect, and points above relative line indicate antagonism between the compounds. 
resistance based on oxidase metabolism [32-34]. As observed in the laboratory, metabolic-based resistance may facilitate synergism between carbamate and repellent when using "two in one" treated materials. In this perspective, these mixtures should be evaluated in areas where mosquitoes show a high and broad range of metabolic-based resistance.

\section{Competing interests}

The authors declare that they have no competing interests.

\section{Authors' contributions}

JB carried out the bioassay studies and drafted most of the manuscript. CP and BL helped to draft the manuscript. SD participated to the bioassay studies. VC conceived the study and helped to draft the manuscript. All authors read and approved the final manuscript.

\section{Acknowledgements}

This study was financially supported by the Agence Nationale pour la Recherche (ANR, programme REAC SEST06 030 0I).

\section{References}

I. Zaim M, Guillet P: Alternative insecticides: an urgent need. Trends Parasitol 2002, 18:161-163.

2. World Health Organization: Safety of pyrethroids for public health use. Geneva: World Health Organization; 2005. WHO/ CDS/WHOPES/GCDPP/2005. I0, WHO/PCS/RA/2005. I

3. World Health Organization: Pesticides and their application for the control of vectors and pests of public health importance (sixth edition). Geneva: World Health Organization; 2006. WHO/ CDS/NTD/WHOPES/GCDPP/2006.I.

4. Hemingway J, Hawkes NJ, McCarroll J, Ranson H: The molecular basis of insecticide resistance in mosquitoes. Ins Bioch $\mathrm{Mol}$ Biol 2004, 34:653-665.

5. N'Guessan R, Corbel V, Akogbeto M, Rowland M: Reduced efficacy of insecticide-treated nets and indoor residual spraying for malaria control in pyrethroid resistance area, Benin. Emerg Infect Dis 2007, I 3:199-206.

6. Marcombe S, Carron A, Darriet F, Etienne M, Philip A, Tolosa M, YpTcha MM, Lagneau C, Yebakima A, Corbel V: Reduced efficacy of pyrethroid space sprays for dengue control in an area of Martinique with pyrethroid resistance. Am J Trop Med Hyg 2009, 80(5):745-75I.

7. Zaim M, Aitio A, Nakashima N: Safety of pyrethroid-treated mosquito nets. Med Vet Entomol. 2002, I 4(I): I-5.

8. Pennetier C, Corbel V, Boko P, Odjo A, N'Guessan R, Lapied B, Hougard JM: Synergy between repellents and non-pyrethroid insecticides strongly extends the efficacy of treated nets against Anopheles gambiae. Malar J 2007, 6:38.

9. Pennetier C, Costantini C, Corbel V, Licciardi S, Dabiré RK, Lapied B, Chandre F, Hougard JM: Mixtures for controlling insecticideresistant malaria vectors. Emerg Inf Dis 2008, I 4(I I): I707-I4.

10. Pennetier C, Corbel V, Hougard JM: Combination of a non-pyrethroid insecticide and a repellent: a new approach for controlling knock-down resistant mosquitoes. Am J Trop Med Hyg 2005, 72(6):739-744.

II. Corbett JR, Wright K, Baillie AC: The biochemical mode of action of pesticides 2nd edition. London: Academic Press; 1984.

12. Ditzen M, Pellegrino M, Vosshall LB: Insect odorant receptors are molecular targets of the insect repellent DEET. Science 2008, 3 19:1838-42.

13. Syed Z, Leal WS: Mosquitoes smell and avoid the insect repellent DEET. Proc Natl Acad Sci USA 2008, I 05(36): I3195-6.

14. Licciardi S, Hervé JP, Darriet F, Hougard JM, Corbel V: Lethal and behavioural effects of three synthetic repellents (DEET, IR3535 and KBR3023) on Aedes aegypti mosquitoes in laboratory assays. Med Vet Entomol 2006, 20(3):288-293.
15. Xue RD, Ali A, Barnard DR: Laboratory evaluation of toxicity of 16 insect repellents in aerosol sprays to adult mosquitoes. J Am Mosq Control Assoc 2003, I 9(3):27I-274.

16. N'Guessan R, Knols BG, Pennetier C, Rowland M: DEET microencapsulation: a slow release formulation enhancing the residual efficacy of bed nets against malaria vectors. Trans $R$ Soc Trop Med Hyg 2008, 102(3):259-262.

17. Lapied B, Pennetier C, Stankiewicz M, Gautier H, Fournier D, Hougard JM, Corbel V: The insect repellent DEET exerts neurotoxic effects through alterations of both neuronal function and synaptic transmission. 5th Forum of European Neuroscience, Vienna, Austria 2006.

18. Lapied B, Stankiewicz M, Pennetier C, Fournier D, Hougard JM, Corbel $V$ : Unexpected neurotoxic effects of the repellent DEET occur through an inhibition of acetylcholinesterase activity in the insect central nervous system. 6th Forum of European Neuroscience, Geneva, Switzerland 2008.

19. Corbel V, Stankiewicz M, Bonnet J, Grolleau F, Hougard JM, Lapied B: Synergism between insecticides permethrin and propoxur occurs through activation of presynaptic muscarinic negative feedback of acetylcholine release in the insect central nervous system. Neurotoxicology. 2006, 27(4):508-519.

20. Corbett JR: The biochemical mode of action of pesticides New York: Academic Press Inc; 1974.

21. Wilkinson CF: Insecticide interactions. In Insecticide biochemistry and physiology Edited by: Wilkinson CF. New York: Plenum press; 1976:605-647.

22. Gunning RV, Moores GD, Devonshire AL: Esterase inhibitors synergize the toxicity of pyrethroids in Australian Helicoverpa armigera. Pest Biochem Physiol 1999, 63:52-62.

23. Kulkarni AP, Hodgson E: Metabolism of insecticides by mixed function oxidase systems. Pharmacol Ther 1980, 8(2):379-475.

24. Bernard C, Philogene BJR: Insecticide synergists: role, importance and perspectives. I Toxicol Environ Health. 1993, 38(2): 199-223.

25. Abbott WS: A method of computing the effectiveness of an insecticide 1925. J Am Mosq Control Assoc. 1987, 3(2):302-303.

26. Raymond M, Prato G, Ratsira D: Probit and Logit Analysis Program version 2.0 Montpellier, France: Praxème R\&D; 1997.

27. Chou TC, Talalay P: Quantitative analysis of dose-effect relationships: the combined effects of multiple drugs or enzyme inhibitors. Adv Enzyme Regul 1984, 22:27-55.

28. Chou TC, Hayball MP: Windows software for dose effect analysis Cambridge: Biosoft; 1996.

29. Constantino L, Rosa E, lley J: The microsomal demethylation of $\mathbf{N}, \mathbf{N}$-dimethylbenzamides. Substituent and kinetic deuterium isotope effects. Biochem Pharmacol I992, 44(4):65 I-658.

30. Constantino L, lley J: Microsomal metabolism of $\mathbf{N}, \mathbf{N}$-diethylm-toluamide (DEET, DET): the extended network of metabolites. Xenobiotica 1999, 29(4):409-416.

31. Corbel V, Stankiewicz M, Pennetier C, Fournier D, Strojan J, Girard E, Dimitrov M, Molgo J, Hougard Jm, Lapied B: A new link between the repellent DEET and its unexpected toxicity in insect and mammalian nervous systems.

32. Muller P, Warr E, Stevenson BJ, Pignatelli PM, Morgan JC, Steven A, Yawson AE, Mitchell SN, Ranson H, Hemingway J, Paine MJ, Donnelly MJ: Field-caught permethrin-resistant Anopheles gambiae overexpress CYP6P3, a P450 that metabolizes pyrethroids. PLoS Genet 2008, 4(I I e I000286 [http://www.plosgenetics.org].

33. Djouaka RF, Bakare AA, Coulibaly ON, Akogbeto MC, Ranson $H$, Hemingway J, Strode C: Expression of the cytochrome P450s, CYP6P3 and CYP6M2 are significantly elevated in multiple pyretrhoid resistant populations of Anopheles gambie s.s. from Southern Benin and Nigeria. BMC Genomics. 2008, I3(9):538.

34. Strode C, Wondji CS, David JP, Hawkes NJ, Lumjian N, Nelson DR, Drane DR, Karunaratne SH, Hemingway J, Black WC, Ranson H: Genomic analysis of detoxification genes in the mosquito Aedes aegypti. Insect Biochem Mol Biol 2008, 38(I): I I 3-I23.

35. Chandre F, Darriet F, Manga L, Akogbeto M, Faye 0, Mouchet J, Guillet P: Status of pyrethroid resistance in Anopheles gambiae sensu lato. Bull World Health Org 1999, 77:230-234.

36. Brengues C, Hawkes NJ, Chandre F, McCarroll L, Duchon S, Guillet P, Manguin S, Morgan JC, Hemingway J: Pyrethroid and DDT cross-resistance in Aedes aegypti is correlated with novel 
mutations in the voltage-gated sodium channel. Med Vet Entomol 2003, 17:87-94.

37. Corbel V, N'Guessan R, Brengues C, Chandre F, Djogbenou L, Martin T, Akogbeto M, Hougard JM, Rowland M: Multiple insecticide resistance mechanisms in Anopheles gambiae and Culex quinquefasciatus from Benin, West Africa. Acta Tropica 2007, | $01: 207-216$.

Publish with Bio Med Central and every scientist can read your work free of charge

"BioMed Central will be the most significant development for disseminating the results of biomedical research in our lifetime. " Sir Paul Nurse, Cancer Research UK

Your research papers will be:

- available free of charge to the entire biomedical community

- peer reviewed and published immediately upon acceptance

- cited in PubMed and archived on PubMed Central

- yours - you keep the copyright

Submit your manuscript here:

http://www.biomedcentral.com/info/publishing_adv.asp 